\title{
PENERAPAN MODEL PEMBELAJARAN ABILITY GROUPING SEBAGAI UPAYA MENINGKATKAN HASIL BELAJAR SISWA PADA MATA PELAJARAN MEKANIKA TEKNIK KELAS X TEKNIK SIPIL SMK NEGERI 5 SURAKARTA Andra Noviana', Sri Sumarni ${ }^{2}$, Waluyo ${ }^{3}$
}

\begin{abstract}
ABSTRAK
Tujuan penelitian ini adalah (1) Untuk mengetahui seberapa besar peningkatan hasil belajar siswa dengan penggunaan model pembelajaran Ability Grouping pada mata pelajaran Mekanika Teknik kelas X Teknik Sipil SMK Negeri 5 Surakarta, (2) Untuk mengetahui seberapa besar peningkatan keaktifan siswa dengan penggunaan model pembelajaran Ability Grouping pada mata pelajaran Mekanika Teknik kelas X Teknik Sipil SMK Negeri 5 Surakarta.

Penelitian ini merupakan penelitian tindakan kelas (PTK) yang dilakukan dalam dua siklus. Teknik analisis data yang digunakan adalah analisis kualitatif.

Hasil penelitian menunjukkan bahwa : (1) penerapan model pembelajaran Ability Grouping dapat meningkatkan hasil belajar siswa. Peningkatan hasil belajar siswa dapat dilihat dari persentase ketuntasan hasil belajar ranah kognitif, ranah afektif dan ranah psikomotorik. Presentase ketuntasan hasil belajar ranah kognitif pra siklus sebesar 68,75\%, siklus I sebesar 78,12\% dan siklus II sebesar 93,75\%. Persentase ketuntasan hasil belajar ranah afektif pra siklus sebesar 53\%, siklus I sebesar 66\% dan siklus II sebesar 87\%. Persentase ketuntasan hasil belajar ranah psikomotorik pra siklus sebesar 56\%, siklus I sebesar 75\% dan siklus II sebesar $87 \%$; (2) penerapan model pembelajaran Ability Grouping dapat meningkatkan keaktifan siswa. Peningkatan keaktifan siswa dapat dilihat dari kenaikan pencapaian aktivitas siswa. Berdasarkan hasil tersebut penerapan model pembelajaran Ability Grouping dapat meningkatkan hasil belajar dan keaktifan siswa kelas X Teknik Sipil A (X TSA) SMK Negeri 5 Surakarta pada mata pelajaran Mekanika Teknik.
\end{abstract}

Kata kunci : Ability Grouping, Hasil belajar, Mekanika Teknik

1 Pendidikan Teknik Bangunan Universitas Sebelas Maret

2 Pembimbing I. Sri Sumarni, S.T., M.T

3 Pembimbing II. Drs. Waluyo, M.Pd 


\title{
THE IMPLEMENTATION OF LEARNING MODEL ABILITY GROUPING TO IMPROVE STUDENTS ACHIEVEMENT IN MECHANIC TECHNIQUE SUBJECT AT THE TENTH GRADE CIVIL ENGINEERING OF SMK N 5 SURAKARTA Andra Noviana', Sri Sumarni ${ }^{2}$, Waluyo ${ }^{3}$
}

\begin{abstract}
The purpose of this research was to (1) improve the increase of students learning achievement Ability Grouping learning model in mechanic technique subject at the tenth grade civil engineering of SMK N 5 Surakarta, (2) improve the increase of students activeness Ability Grouping learning model in mechanic technique subject at the tenth grade civil engineering of SMK N 5 Surakarta.

This is Classroom Action Research (CAR) was conducted in two cycles. The technique of data analysis used was qualitative analysis.

The results of the research showed that: (1) The implementation of Ability Grouping learning model can improve students learning achievement. The improvement of students learning achievement can be seen from the percentage learning result by cognitive, affective, and psychomotor. The percentage of precycle cognitive learning result was 68,75\%, the first cycle was 78,12\% and second cycle was 93,75\%. Affective learning result pre-cycle was 53\%, the first cycle was 66 $\%$ and the second cycle was $87 \%$. Psychomotor learning result pre-cycle was $56 \%$, the first cycle was $75 \%$ and the second cycle was $87 \%$. (2) The implementation of Ability Grouping learning model can improve students activeness. Improve of students activeness can be seen from the increase of students activity. The based on these result was the implementation of Ability Grouping learning model can improve achievement and activeness tenth grade civil engineering students of SMK N 5 Surakarta in mechanic technique subject.
\end{abstract}

Keyword : Ability Grouping, Achievement, Mechanic Technique

1 Vocational Technical Education, Sebelas Maret University

2 Adviser I. Sri Sumarni, S.T., M.T

3 Adviser II. Drs. Waluyo, M.Pd 


\section{PENDAHULUAN}

Pendidikan memegang peranan penting dalam menentukan kemajuan dan kecerdasan suatu bangsa. Pendidikan merupakan dasar dalam pembentukan kepribadian, sikap, tingkah laku serta norma maupun nilai budaya dalam diri seorang individu. Pendidikan dapat diperoleh melalui jalur pendidikan formal maupun jalur pendidikan non formal. Sekolah merupakan lembaga formal yang dituntut untuk membimbing dan melaksanakan pembelajaran yang baik dengan tujuan menghasilkan generasi muda yang terampil, cerdas, dan bermoral tinggi.

Proses pembelajaran pada dasarnya membantu setiap siswa dalam mengembangkan potensi yang ada pada dirinya. Proses pembelajaran di jaman sekarang ini harus mengalami perubahan dalam penyampaian materi maupun dalam metode yang digunakan. Siswa harus berperan aktif dalam proses pembelajaran, sedangkan guru berperan membimbing dan fasilitator bagi siswa.

Menurut Oemar Hamalik (2011: 9), tugas guru sebagai fasilitator adalah: memberikan kemudahan belajar kepada seluruh peserta didik, agar mereka dapat belajar dalam suasana menyenangkan, gembira, penuh semangat, tidak cemas dan berani mengemukakan pendapat secara terbuka. Oleh karena itu, guru sebagai fasilitator dalam mengembangkan bahan ajar mampu memberikan suasana yang menyenangkan serta dapat meningkatkan kemampuan belajar siswa. Hal itu yang menjadi dasar keberhasilan proses pembelajaran.

Proses pembelajaran di SMK Negeri 5 Surakarta, khususnya kelas X Teknik Sipil tingkat keaktifan siswa untuk memahami dan mengembangkan materi pembelajaran perlu ditingkatkan. Keaktifan belajar antara peserta didik dengan peserta didik lainnya maupun peserta didik dengan guru belum meningkat. Hal itu berdampak pada belum meningkatnya hasil belajar siswa.

Data tahun ajaran 2014/2015 menunjukkan bahwa pada mata pelajaran Mekanika Teknik siswa yang nilainya kurang dari batas minimal 75 sebanyak 31,25\%. Batas minimal Kriteria Ketuntasan Minimal (KKM) untuk mata pelajaran Mekanika Teknik adalah 75, sehingga perlu dilakukan penerapan model pembelajaran yang lain sebagai upaya untuk meningkatkan aktivitas dan hasil belajar siswa.

Penyebab dari kurangnya hasil belajar dan keaktifan siswa yaitu metode pembelajaran yang digunakan guru, guru menjelaskan dan siswa mencatat sehingga pembelajaran berpusat kepada guru. Penyebab lain yang timbul yaitu dari siswa yang kurang antusias dalam mengikuti pelajaran dan kurang memahami materi yang dijelaskan oleh guru.

Untuk mengatasi masalah tersebut maka perlu adanya suatu 
model pembelajaran yang sesuai untuk meningkatkan hasil belajar dan keaktifan siswa, model pembelajaran ini harus meningkatkan antusias siswa agar siswa dapat merasa nyaman selama proses pembelajaran. Melalui model pembelajaran Ability Grouping diharapkan dapat meningkatkan hasil belajar dan keaktifan siswa.

Ability Grouping termasuk pembelajaran Cooperative Learning. Menurut Jhonson dan Jhonson dalam (Isjoni, 2010 : 17) Cooperative Learning adalah mengelompokan siswa di dalam kelas ke dalam suatu kelompok kecil agar siswa dapat bekerja sama dengan kemampuan maksimal yang mereka miliki dan mempelajari satu sama lain dalam kelompok tersebut. Ability Grouping merupakan pembelajaran yang lebih menekankan bagaimana peserta didik dapat mencerna dan mengemukakan sebuah hasil pembahasan materi pelajaran secara berkelompok dengan ruang lingkup di dalam kelas, dengan tujuan untuk mengetahui keaktifan dan mendapatkan hasil belajar siswa.

Ability Grouping merupakan strategi belajar dengan siswa sebagai kelompok kecil dengan tingkat kemampuan yang berbeda. Siswa dalam menyelesaikan tugas kelompok yang diberikan guru harus saling bekerja sama dan saling membantu untuk memahami materi pelajaran.

Model pembelajaran ini untuk memotivasi siswa agar berani mengemukakan pendapat, menghargai pendapat teman, dan saling memberi pendapat.

Menurut Anita Lie (2010 : 39) dalam menerapkan model Ability
Grouping mempunyai beberapa keuntungan antara lain: 1) Saling ketergantungan positif antar kelompok. 2) Tanggung jawab perorangan karena harus mengeluarkan pendapat dan mengerjakan tugas rumah. 3) Tatap muka antara sesama anggota kelompok dan anggota kelas dalam melakukan diskusi bersama. 4) Komunikasi antar anggota kelompok dan anggota kelas semakin erat. 5) Mempermudah evaluasi antara kelompok dan antar anggota kelompok.

Suprijono (2013: 5), hasil belajar adalah pola-pola perbuatan, nilai-nilai pengertian-pengertian, sikap-sikap, apresiasi dan keterampilan. Menurut Bloom hasil belajar mencakup kemampuan kognitif, afektif dan psikomotorik. Domain kognitif knowledge (pengetahuan, ingatan), comprehension (pemahaman, menjelaskan, meringkas, contoh), application (menerapkan), analysis (menguraikan, menentukan hubungan), synthesis (mengorganisasikan, merencanakan, membentuk bangunan baru), dan evaluation (menilai). Domain afektif adalah recevieng (sikap menerima), responding (memberikan respons), valuing (nilai), organization (organisasi), characterization (karakterisasi). Domain psikomotor meliputi initiatory, pre-routine, dan rountinized. Psikomotor juga mencakup keterampilan produktif, teknik, fisik, sosial, manajerial dan intelektual. Sementara menurut Lindgren dalam (Suprijono, 2013: 6) hasil pembelajaran meliputi 
kecakapan, informasi, pengertian dan sikap.

Keaktifan siswa dalam proses pembelajaran akan menyebabkan interaksi yang tinggi antara guru dengan siswa. Hal ini akan mengakibatkan suasana kelas menjadi nyaman dan kondusif, dimana masingmasing siswa dapat melibatkan kemampuannya semaksimal mungkin. Aktivitas yang timbul dari siswa akan mengakibatkan pula terbentuknya pengetahuan dan keterampilan yang akan mengarah pada peningkatan prestasi (Hakim, 2013: 5).

Menurut Jessica (2009: 1-2) ada 2 faktor yang mempengaruhi aktivitas belajar siswa yaitu : 1) Faktor Internal (dari dalam individu yang belajar) Faktor yang mempengaruhi kegiatan ini lebih ditekankan pada faktor dari dalam individu yang belajar. Adapun faktor yang mempengaruhi kegiatan tersebut adalah faktor psikologis antara lain yaitu motivasi, perhatian, pengamatan, tanggapan dan lain sebagainya. 2) Faktor Eksternal (dari luar individu yang belajar) Pencapaian tujuan belajar perlu diciptakan adanya sistem lingkungan belajar yang kondusif. Hal ini akan berkaitan dengan faktor dari luar siswa. adapun faktor yang mempengaruhi adalah mendapatkan pengetahuan, pemahaman konsep dan keterampilan, dan pembentukan sikap.

Menurut Jumanto (2011), bahwa ketuntasan hasil belajar kognitif siswa pada siklus I $65 \%$ dan siklus II $84,21 \%$. Ketuntasan hasil belajar siswa ranah afektif siklus I $60 \%$ dan siklus II 73,68 \%. Ketuntasan hasil belajar ranah psikomotorik siswa siklus I $65 \%$ dan siklus II 78,94\%.

Berdasarkan latar belakang dan kajian teori yang telah dipaparkan sebelumnya, maka tujuan dari penelitian ini adalah sebagai berikut: (1) untuk mengetahui peningkatan hasil belajar siswa dengan penggunaan model pembelajaran Ability Grouping pada mata pelajaran Mekanika Teknik kelas X Teknik Sipil SMK Negeri 5 Surakarta, (2) untuk mengetahui peningkatan keaktifan siswa dengan penggunaan model pembelajaran Ability Grouping pada mata pelajaran Mekanika Teknik kelas X Teknik Sipil SMK Negeri 5 Surakarta.

\section{METODE PENELITIAN}

Penelitian ini dilaksanakan di SMK Negeri 5 Surakarta yang beralamat di Jl. LU. Adi Sucipto No. 42 Surakarta Telp. (0271) 713916 Fax 727068 Surakarta 57143. Penelitian ini merupakan penelitian tindakan kelas (PTK). Ada tiga kata yang membentuk pengertian PTK, yaitu penelitian, tindakan dan kelas. Penelitian adalah kegiatan mencermati suatu objek dengan menggunakan aturan metodelogi tertentu untuk memperoleh data atau informasi yang bermanfaat dalam meningkatkan mutu suatu hal, serta menarik minat dan penting bagi peneliti. Tindakan adalah kegiatan yang sengaja dilakukan dengan tujuan tertentu. Sedangkan kelas adalah sekelompok siswa yang dalam waktu yang sama menerima pelajaran dari seorang guru (Arikunto, 2004). Subjek penelitian ini adalah siswa kelas $\mathrm{X}$ Teknik Sipil A (X TSA) SMK Negeri 5 Surakarta Tahun Ajaran 2015/2016. 
Kelas X Teknik Sipil A (X TSA) terdapat 32 siswa yang terdiri dari 31 siswa laki-laki dan 1 siswa perempuan. Teknik pengumpulan data pada penelitian ini meliputi (1) observasi, (2) dokumen dan (3) tes. Teknik analisis data pada penelitian ini adalah teknik analisis kualitatif. Indikator kinerja penelitian hasil belajar siswa untuk ranah kognitif, ranah afektif dan ranah psikomotorik nilai yang ditargetkan 75 dengan presentase $75 \%$. Prosedur (1) pra siklus dan (2) siklus, terdapat dua siklus.

\section{HASIL PENELITIAN DAN PEMBAHASAN}

Hasil tindakan pra siklus siswa kurang antusias dalam mengikuti pembelajaran baik saat penyampaikan materi maupun diskusi kelompok.

Hasil aktivitas siswa pra siklus ditunjukkan seperti pada gambar 1 .

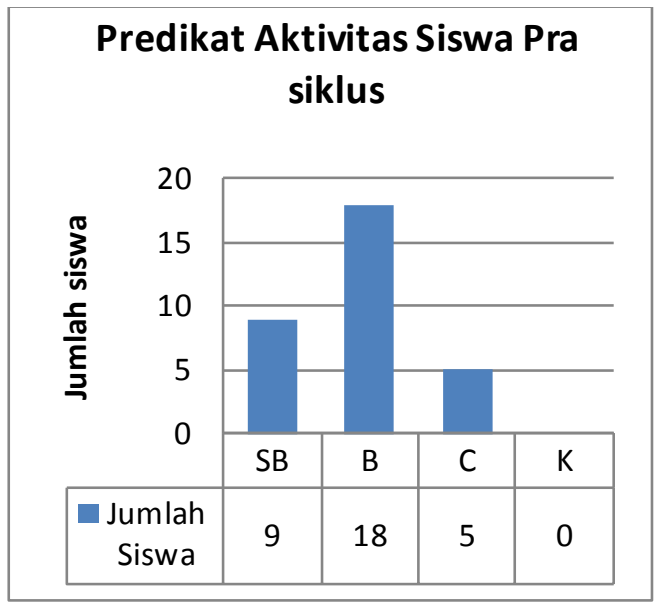

Gambar 1. Diagram Predikat Aktivitas Siswa Prasiklus

Aktivitas siswa pada tahap prasiklus diketahui 5 siswa berpredikat cukup (C), 18 siswa berpredikat baik
(B), dan 9 siswa berpredikat sangat baik (SB), dan tidak ada yang berpredikat kurang (K).

Hasil belajar siswa pra siklus dengan ketuntasan nilai $\geq 75$ dengan presentase $75 \%$ pada ranah kognitif, afektif, dan psikomotorik belum memenuhi target yang ditetapkan.

Hasil belajar siswa pra siklus ranah kognitif, ranah afektif dan ranah psikomotorik ditunjukkan seperti pada gambar 2, 3, dan 4.

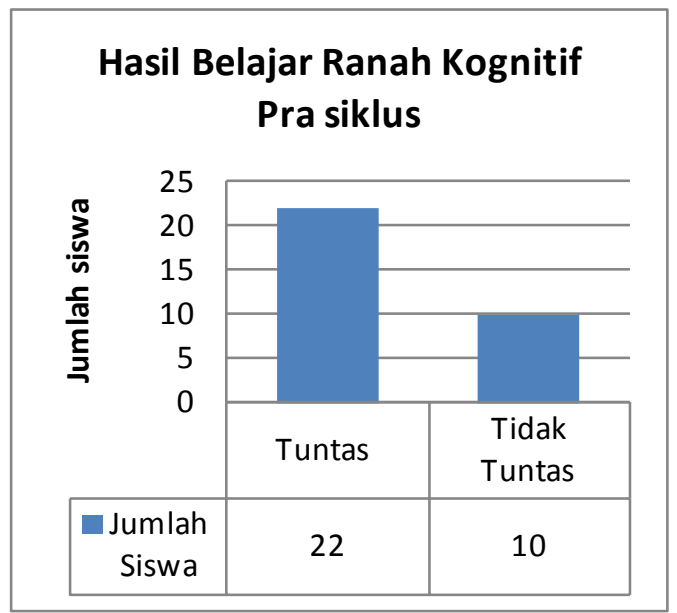

Gambar 2. Diagram Persentase Hasil Belajar Ranah Kognitif Prasiklus

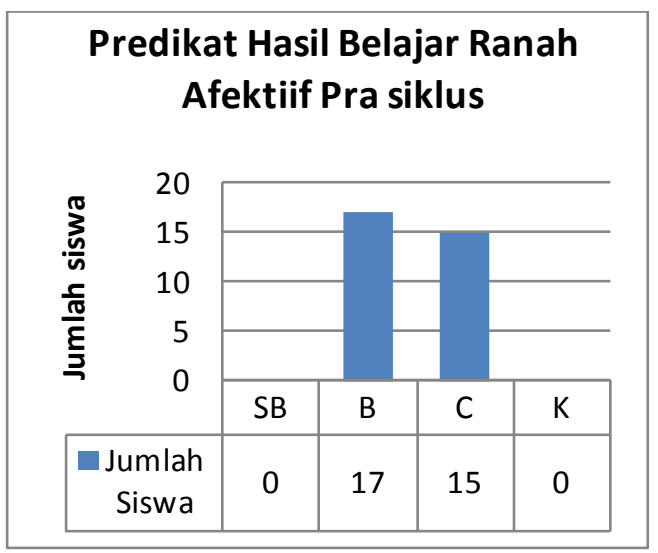

Gambar 3. Diagram Predikat Hasil Belajar Ranah Afektif Prasiklus 


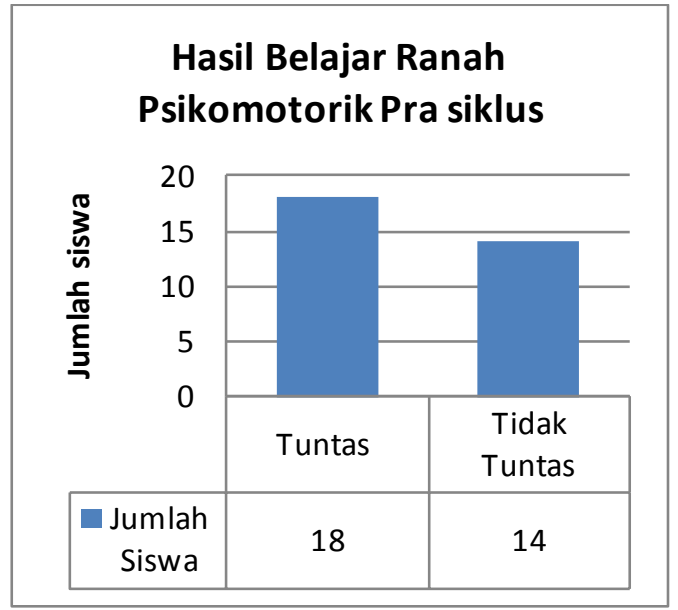

Gambar 4. Diagram Persentase Hasil Belajar Ranah Psikomotorik Prasiklus

Hasil belajar ranah kognitif didapat rata-rata sebesar 78,43 dengan presentase ketuntasan sebesar 68,75\%, 22 siswa dari 32 siswa. Hasil belajar ranah afektif siswa yang mendapat predikat baik sebanyak 17 siswa dari 32 siswa. Hasil belajar ranah psikomotorik didapat rata-rata sebesar 74,68 dengan presentase ketuntasan sebesar 56\%, 18 siswa dari 32 siswa.

Hasil belajar dan keaktifan siswa yang diperoleh masih belum memnuhi indikator yang telah ditetapkan. Untuk menumbuhkan keaktifan siswa dalam kegiatan pembelajaran maka diterapkan model pembelajaran Ability Grouping.

Pelaksanaan siklus I keaktifan siswa dan hasil belajar siswa mengalami peningkatan.

Hasil aktivitas siswa siklus I ditunjukkan seperti pada gambar 5 .

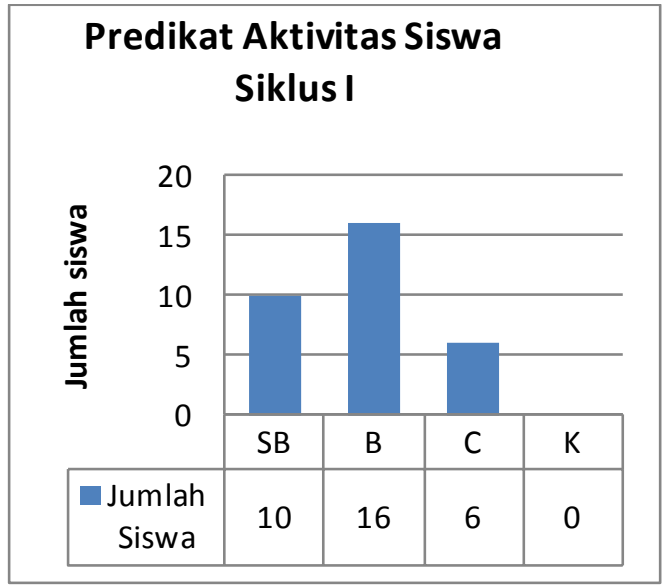

Gambar 5. Diagram Predikat Aktivitas Siswa Siklus I

Hasil belajar siswa siklus I ranah kognitif, ranah afektif dan ranah psikomotorik ditunjukkan seperti pada gambar 6, 7, dan 8 .

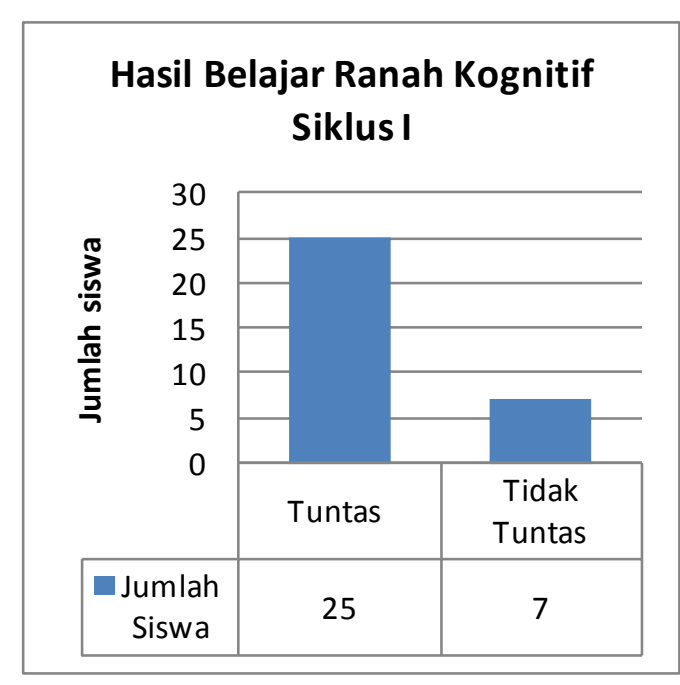

Gambar 6. Diagram Persentase Hasil Belajar Ranah Kognitif Siklus I 


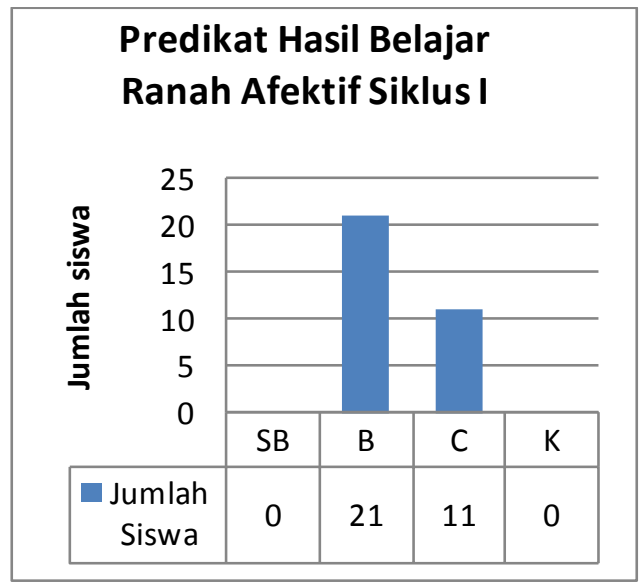

Gambar 7. Diagram Predikat Hasil Belajar Ranah Afektif Siklus I

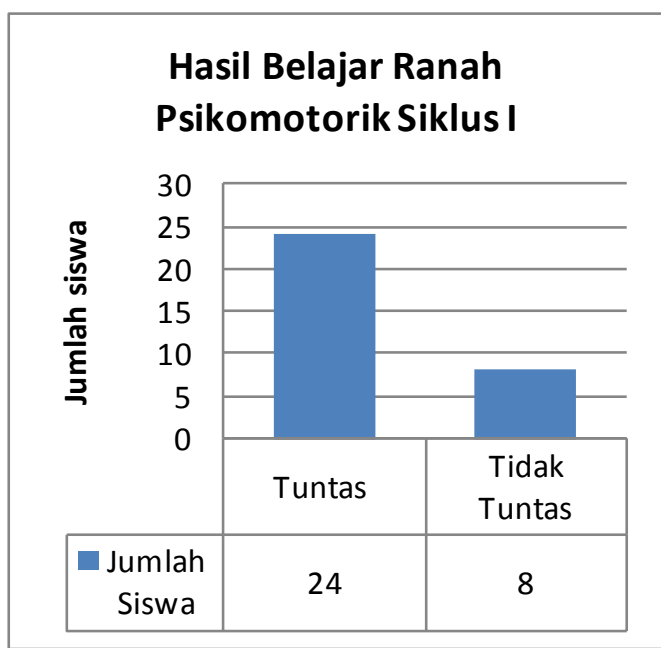

Gambar 8. Diagram Persentase Hasil Belajar Ranah Psikomotorik Siklus I

Hasil belajar ranah kognitif didapat rata-rata sebesar 78,65 dengan presentase ketuntasan sebesar 78,12\%, 25 siswa dari 32 siswa. Hasil belajar ranah afektif siswa yang mendapat predikat baik sebanyak 21 siswa dari 32 siswa. Hasil belajar ranah psikomotorik didapat rata-rata sebesar 76,56 dengan presentase ketuntasan sebesar $75 \%$, 24 siswa dari 32 siswa.
Hasil belajar dan keaktifan siswa mengalami peningkatan. Siswa yang kurang aktif dalam diskusi sudah mulai aktif. Hasil belajar siswa mengalami peningkatan baik ranah kognitif, ranah afektif dan ranah psikomotorik. Penerapan model pembelajaran Ability Grouping dapat meningkatkan hasil belajar siswa dan keaktifan siswa.

Pada saat pelaksanaan siklus II hasil belajar dan keaktifan siswa mengalami peningkatan.

Hasil aktivitas siswa siklus II ditunjukkan seperti pada gambar 9.

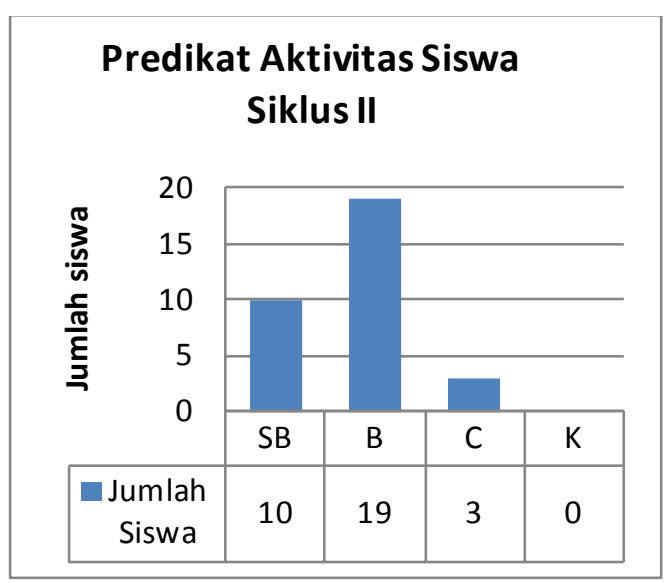

Gambar 9. Diagram Predikat Aktivitas Siswa Siklus II

Hasil belajar siswa siklus I ranah kognitif, ranah afektif dan ranah psikomotorik ditunjukkan seperti pada gambar 10, 11, dan 12. 


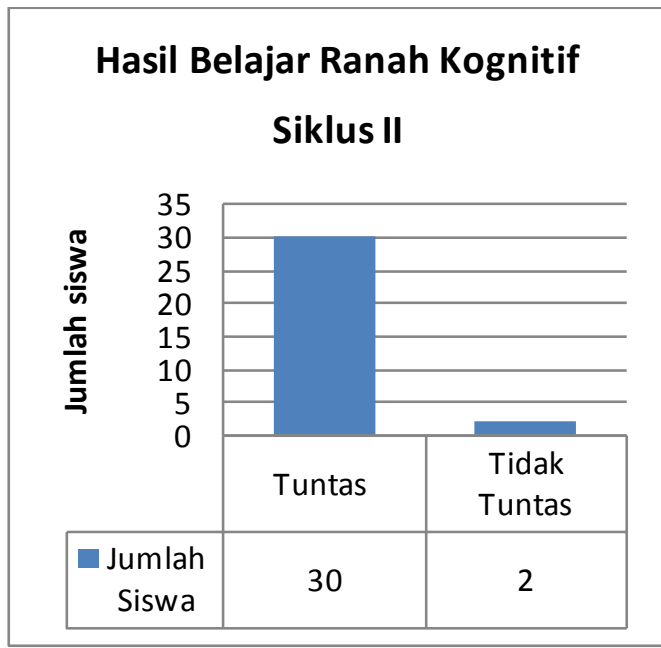

Gambar 10. Diagram Persentase Hasil Belajar Ranah Kognitif Siklus II

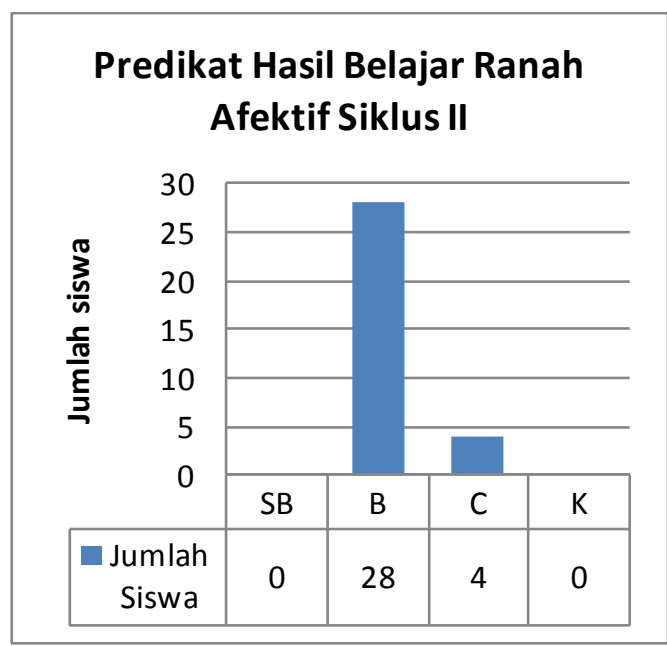

Gambar 11. Diagram Predikat Hasil Belajar Ranah Afektif Siklus II

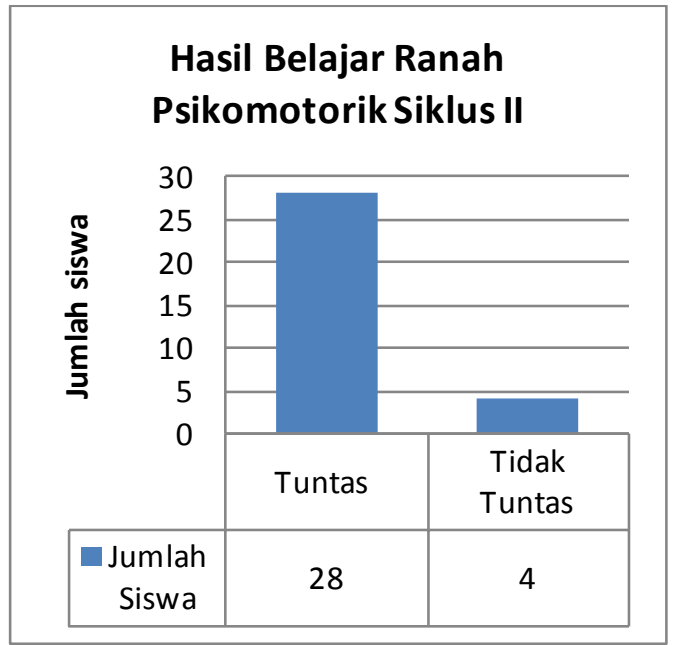

Gambar 12. Diagram Persentase Hasil Belajar Ranah Psikomotorik Siklus II

Hasil belajar ranah kognitif didapat rata-rata sebesar 80,93 dengan presentase ketuntasan sebesar 93,75\%, 30 siswa dari 32 siswa. Hasil belajar ranah afektif siswa yang mendapat predikat baik sebanyak 28 siswa dari 32 siswa. Hasil belajar ranah psikomotorik didapat rata-rata 78,43 dengan presentase ketuntasan sebesar 87\%, 28 siswa dari 32 siswa.

Hasil belajar dan keaktifan siswa siklus II mengalami peningkatan sangat baik. Siswa memperhatikan penjelasan guru saat kegiatan pembelajaran. Hasil belajar ranah kognitif, ranah afektif dan ranah psikomotorik mengalami peningkatan baik dari presentase ketuntasan maupun rata-rata kelas.

Hasil penelitian dengan menerapkan model pembelajaran Ability Grouping pada kelas X Teknik Sipil A (X TSA) SMK Negeri 5 Surakarta terbukti dapat meningkatkan hasil belajar dan keaktifan siswa. Semua aspek hasil belajar seperti 
ranah kognitif, ranah afektif dan ranah psikomotorik mengalami peningkatan nilai ketuntasan. Hal ini sejalan dengan hasil penelitian yang dilakukan oleh beberapa peneliti sebelumnya. Mereka menyimpulkan bahwa dengan menerapkan model pembelajaran Ability Grouping dapat meningkatkan hasil belajar siswa.

\section{SIMPULAN}

Berdasarkan hasil penelitian dengan menerapkan model pembelajaran Ability Grouping pada mata pelajaran Mekanika Teknik dengan materi menyusun gaya siswa kelas X TSA SMK Negeri 5 Surakarta dapat disimpulkan bahwa: (1) Model pembelajaran Ability Grouping dapat memperbaiki proses pembelajaran dan goalnya untuk meningkatkan hasil belajar siswa kelas $\mathrm{X}$ TSA SMK Negeri 5 Surakarta pada mata pelajaran Mekanika Teknik, (2) Model pembelajaran Ability Grouping dapat meningkatkan keaktifan siswa kelas $\mathrm{X}$ TSA SMK Negeri 5 Surakarta pada mata pelajaran Mekanika Teknik.

\section{SARAN}

Penelitian selanjutnya dapat menggunakan beberapa observator agar penelitian lebih maksimal.

Perlunya persiapan materi yang lebih mendalam dan alat peraga sebagai penunjang pelaksanaan model pembelajaran Ability Grouping.

\section{DAFTAR PUSTAKA}

Anita, Lie. (2010). Cooperative learning : Mempraktikkan Cooperative Learning Di Ruang-Ruang Kelas. Jakarta : PT. Grasindo.

Hakim, Z. (2013). Keaktifan Belajar. Diperoleh 05 Maret 2015 dari http://www.zainalhakim.w eb.id/keaktifan-siswa-dalamproses-pembelajaran.html. Diakses 18 Maret 2015.

Isjoni. (2010). Cooperative learning : Efektivitas Pembelajaran Kelompok. Bandung : Alfabeta.

Jumanto. (2011). Penerapan Model Pembelajaran Ability Grouping Sebagai Upaya Meningkatkan Hasil Belajar Siswa Pada Mata Pelajaran Menggambar Teknik Bangunan Di Kelas XI Teknik Konstruksi Kayu (TKK) SMK Negeri 2 Surakarta. Surakarta : Universitas Sebelas Maret. Skripsi.

Jessica. (2009). Pengertian Hasil Belajar.http:/techonly13.wordp ress.com/2009/07/04/pengertia nhasilbelajar/ (27/07/13). Diakses 18 Maret 2015.

Oemar, Hamalik. (2011). Kurikulum dan Pembelajaran. Jakarta : PT Bumi Aksara.

Sanjaya,W. (2013). Penelitian Tindakan Kelas. Jakarta: Kencana.

Suprijono,A. (2013). Cooperative Learning Teori Dan Aplikasi Paikem. Yogyakarta: Pustaka Pelajar. 